\title{
Enseñanza de la historia y memoria ejemplar
}

\author{
Fernando Bárcena Orbe \\ Universidad Complutense de Madrid
}

\begin{abstract}
The intention of this article is to articulate a series of reflections about the teaching of history, using as a frame of reference the principle of discontinuity in the narrativity of the historical narrative and the modern crisis in the transmission of memorable experiences that the information society only exacerbates. Specifically, the article addresses the analysis of the role of memory and the reading of the past in the teaching of history. The article argues that an effort to connect the teaching history to what is singular would make history more effective to the extent that, through the narrative, a discontinuity in consciousness would be introduced in the educative process.
\end{abstract}

Keywords: education and discontinuity; history and memory; narrativity and experience

\section{RESUMEN}

El propósito de este artículo es articular una serie de reflexiones acerca de la enseñanza de la historia teniendo como marco de referencia el principio de discontinuidad en la narración de los acontecimientos históricos y la crisis moderna en la transmisión de experiencias memorables que la sociedad de la información no hace más que incrementar. El artículo se ocupará preferentemente del análisis del papel de la memoria y la lectura del pasado en la enseñanza de la historia. El artículo defiende que un esfuerzo de conexión de la enseñanza de la historia a la singularidad de los acontecimientos que se transmiten volverá efectiva a la historia misma, en la medida en que a través de su transmisión narrativa se introduzca lo discontinuo en la conciencia que se forma en la enseńanza y en la práctica educativa.

Descriptores: educación y discontinuidad; historia y memoria; narratividad y experiencia

\section{RÉSUMÉ}

Le but de cet article est d'articuler une série de réflexions sur l'enseignement de l'histoire en ayant comme cadre de référence le principe de discontinuité dans la narration des événements historiques et la crise moderne dans la transmission d'expériences mémorables que la société de l'information ne fait pas plus qu'augmenter. L'article s'occuperait préférentiellement de l'analyse du rôle de la mémoire et la lecture du passé dans l'enseignement de l'histoire. L'article défend qu'un effort de connexion de l'enseignement de l'histoire à la singularité des événements qui sont transmis retournera effectif à l'histoire elle-même, dans la mesure où à travers sa transmission narrative on introduit ce qui est discontinu dans la conscience qui se forme dans l'enseignement et dans la pratique éducative.

Mots-cléfs: education et discontinuité; histoire et mémoire; narrativité et experience 
Eso de contar historias, de contarlas de verdad, tiene que haber sido de épocas que yo no recuerdo. Yo nunca oí a nadie contar nada. (Rainer Maria Rilke, Los apuntes de Malte Laurids Bridge.)

Sabíamos muy bien lo que era experiencia, los mayores se la habían pasado siempre a los más jóvenes. En términos breves, con la autoridad de la edad, en proverbios; prolijamente, con la locuacidad, en historias; a veces como una narración de países extraños, junto a la chimenea, ante hijos y nietos. Pero ¿dónde ha quedado todo eso? ¿Quién encuentra hoy gentes capaces de narrar como es debido? ¿Acaso dicen hoy los moribundos palabras perdurables que se transmiten como un anillo, de generación a generación?

(Walter Benjamin, Experiencia y pobreza.)

\section{Introducción}

$\mathrm{N}^{\circ}$ ES FÁCIL SABER HASTA QUÉ PUNTO A TRAVÉS de la enseñanza de la historia es posible dar respuesta a algunas preguntas principales que los filósofos se han ido planteando, y que todavía nos inquietan. Preguntas, por ejemplo, del tipo: ¿qué es la "humanidad"? ¿Es la infinita diversidad del género humano o la cualidad distintiva que reúne a todos los hombres y mujeres? ¿Cómo concebir la singularidad de cada ser y su igual pertenencia a la comunidad humana sin pensar al mismo tiempo en un "senti miento" de humanidad? Abrir la investigación histórica y su enseñanza a estas pregun tas probablemente signifique aceptar que una corriente subterránea de filosofía moral y política recorre la entraña misma de lo histórico. Pero, tras un siglo atroz como el que acabamos de dejar-un siglo de extremos-abrir las entrańas de la historia a la pregunta por la condición humana impone la obligación del recuerdo de lo inhumano.

La enseñanza de lo inhumano, a través de la historia, precisa una transmisión que ponga el acento en la memoria, en la experiencia y en la singularidad de los acontecimientos. Como seńaló Foucault (2000), las palabras dichas en la crónica histórica no guardan su sentido de una forma inmutable, ni los deseos su dirección inicial, ni las ideas su lógica primera. Por eso, la investigación y la enseñanza de la historia requiere sus cautelas: "Localizar la singularidad de los acontecimientos, fuera de toda finalidad monótona" (p.I2). Pero si de lo que se trata es de mostrar la singularidad de los acontecimientos, entonces la historia a transmitir no sería ya una serie de objetivaciones, sino una tarea por hacer, un trabajo de reelaboración, es decir, en sí misma, un mostrar la ficción y el puro acontecer. La misma pregunta por lo humano, en paralelo a lo inhumano que la historia misma nos trae, muestra hasta qué punto el ser humano se ha formado con la historia y con sistemas cerrados de saber que creen que pueden seguir rastreando la esencia del ser humano como algo a-histórico. Así que habría que invertir los términos y decir: no se trata de hacer de la historia un objeto de pensamiento, sino de rescatar al pensamiento mismo como un acontecer de la historia. Entonces, la historia sería el conjunto de acontecimientos que dan a pensar, lo que está por pensar todavía, lo no 
dicho; pero sería también lo que, al haber excitado nuestro pensamiento, nos permite hacer experiencia y nos advierte de que no es sostenible ya una idea del tiempo de la historia como continuidad. Probablemente, las atrocidades del siglo XX nos muestran que lo discontinuo es la condición estrictamente contemporánea en la que nos es dado pensar después de los totalitarismos. ${ }^{1}$

De acuerdo con esta advertencia, el objetivo de este artículo será, por una parte, articular una serie de reflexiones acerca de la enseñanza de la historia teniendo como marco esta primera meditación y como excusa coyuntural el deseo de revitalizar la formación de carácter "humanista" en el sistema educativo, lo que en España se ha traducido en diversas reformas sobre las humanidades y, en concreto, sobre la enseńanza de la historia. Pero se tratará también de analizar el papel de la memoria y la lectura del pasado en la enseñanza (y la investigación) histórica. De acuerdo con esto último, lo que en el fondo nos va a ocupar aquí será, entonces, el análisis de las relaciones entre historia y memoria, relaciones que, en el seno de nuestras llamadas "sociedades de la información”, resultan sumamente controvertidas, pues si la memoria pide una cierta durabilidad, la información permanece atrapada en el instante presente. Desde este punto de vista, vincular la enseñanza de la historia a la singularidad de los acontecimientos que se transmiten no será otra cosa que volver efectiva a la historia misma, en la medida en que a través de su transmisión narrativa-esa es la apuesta-se introduzca lo discontinuo en la conciencia que se forma en la enseńanza y en la práctica educativa.

\section{Enseñanza de la historia y transmisión de experiencias}

Señala el filósofo Agamben (200I) que "en la actualidad, cualquier discurso sobre la experiencia debe partir de la constatación de que ya no es algo realizable. Pues así como fue privado de su biografía, al hombre contemporáneo se le ha expropiado su experiencia” (p. 7). Dentro de las estructuras específicamente modernas nos encontramos, en efecto, con que se ha vuelto sumamente difícil hacer experiencia personal de aquello que nos afecta. En la sociedad moderna asistimos a un secuestro de la experiencia. Por otra parte, el auge cada vez mayor de la "sociedad de la información" obliga a la mente humana a trabajar, casi exclusivamente, procesando información, con lo que la capacidad para la memoria y el recuerdo de lo memorable se ha ido deteriorando cada vez más. Finalmente, nuestras sociedades viven pendientes, fundamentalmente, del espacio y la aceleración, pero no del tiempo (pasado, presente, futuro) y la lentitud, y la vida humana es en ella una vida más espacial que espacialmente atravesada por la experiencia del tiempo. Ahora bien, "como saben todos los nińos-nos recuerda Alberto Manguel (200I) - el mundo de la experiencia (como el bosque de Alicia) es innominado, y vagamos por él en un estado de perplejidad, la cabeza llena de balbuceos de conocimiento e intuición" (pp. 26-27).

La educación, y de un modo específico la lectura, nos ayuda en la tarea de aprender a nombrar lo que nos pasa, la experiencia que hacemos en lo que nos acontece. Así, es tarea de cada lector aprender a decir lo que le acontece. Poco a poco, entonces, el acontecimiento-la experiencia que hacemos con el mundo y la experiencia que el mundo 
hace en nosotros - nos proporciona un saber de experiencia, al mismo tiempo que se deja nombrar mediante las palabras y se hace por ello pensable. Sólo que lo grave de este "saber de experiencia" es que, si es verdadero, como decía María Zambrano (1995), "llega después, no sirve y es intransferible" (p.15). Muy probablemente, entonces, lo que en realidad sucede es que el verdadero acontecimiento, la auténtica experiencia, se deja nombrar y pensar de otro modo, de una forma que no es estrictamente ni exclusivamente conceptual, esto es, por unas palabras y por un pensamiento de un orden distinto, quizá de una palabra pensada-es decir, de un logos-que se sitúa en el orden de lo poético.

Este orden poético nos proporciona una gramática nueva; dicho con G. Steiner (200I), esta gramática es una organización articulada de la percepción, la reflexión y la experiencia, la estructura nerviosa misma de la conciencia humana cuando es capaz de comunicarse consigo misma y con otros (p.I5). En último término, esta gramática es una "gramática de la creación", una gramática, entonces, de lo erótico, del "intelecto formador" y de la psique bajo la forma del eros. Para desarrollar en nosotros esta condición gramatical, esta articulación de la percepción, la reflexión y la experiencia, lo que precisamos es una manera distinta de pensar la educación, una en la que, dicho ahora pedagógicamente, aceptemos el reto de introducir verdaderos contenidos de conciencia en el sujeto que se educa. Lo diré con J. García Carrasco y A. García del Dujo (200I):

El interés del pedagogo por el sujeto se centra en aportar contenidos de conciencia y en favorecer el posicionamiento del sujeto respecto a esos contenidos; en última instancia, la ontología de los procesos educacionales viene dada por el sistema de sucesos en la subjetividad y la Pedagogía queda constituida por el sistema de acciones que pretenden favorecer acontecimientos en la subjetividad. (p.62)

Las anteriores palabras de Agamben tienen relación con el diagnóstico que Walter Benjamin (1989) hiciese en la década de los años treinta de una cierta "pobreza de experiencia” en la época moderna. En un escrito de I933 Benjamin conectó la sensación de vacío y angustia existencial experimentada por la generación sobreviviente a la Primera Guerra Mundial con uno de los rasgos característicos de la crisis de la modernidad: la pérdida de capacidad narrativa. Esta incapacidad de contar historias creíbles, ese empobrecimiento de quienes venían de las trincheras de la Primera Guerra Mundial, en la que tantas cosas habían ocurrido y tan poco parecía haberles pasado a los que regresaban - o tan mudos les dejó - tiene mucha más relación con la crisis de la filosofía de la historia y la actual crisis de su enseńanza de lo que estamos dispuestos a reconocer. Esa incapacidad narrativa, y la consiguiente crisis de la novela que le sucedió, ya habían sido registradas en el terreno literario a principios de siglo por autores vieneses como Hoffmansthal, Rilke, Kafka o el mismo Musil, "herederos de la vivencia de fragmentariedad del mundo explorada por los románticos”, dice Manuel Barrios (2002), los cuales hicieron del extravío del lenguaje y del sujeto uno de los motivos literarios más sólidos (p. 50). Lo que Benjamin aportó en su escrito era aplicar esta crisis literaria 
de la narratividad al ámbito más amplio y extenso de la experiencia vivida, hasta el punto que esta incapacidad para contar historias podía interpretarse también como una pérdida de la efectividad de la memoria y de su transmisión, lo que nos situaría ante una crisis radical de la enseńanza y en un plano, en apariencia, de nostalgia por un pasado ya olvidado en el que era efectivamente posible compartir la experiencia de la memoria histórica entre las generaciones a través de los relatos:

Sabíamos muy bien lo que era experiencia, los mayores se la habían pasado siempre a los más jóvenes. En términos breves, con la autoridad de la edad, en proverbios; prolijamente, con la locuacidad, en historias; a veces como una narración de países extraños, junto a la chimenea, ante hijos y nietos. Pero ¿dónde ha quedado todo eso? ¿Quién encuentra hoy gentes capaces de narrar como es debido? ¿Acaso dicen hoy los moribundos palabras perdurables que se transmiten como un anillo, de generación a generación? (Benjamin, p. I67)

La actual crisis del lenguaje simbólico y, al mismo tiempo, de la narración, la crisis del relato que ya había puesto de manifiesto Benjamin en otro importante texto, parece comportar inevitablemente una crisis de sentido. Esta crisis de sentido afecta de lleno a la problemática de la enseńanza de la historia y su dimensión educativa. En su ensayo "El narrador", Benjamin relaciona crisis de la narración con la irrupción de una forma de comunicación típicamente burguesa: la información. Ésta no necesita, a diferencia de la narración, de la experiencia. En un universo en el que la narración está radicalmente en crisis tiene lugar también una crisis de la experiencia, y viceversa. En la modernidad ha experiencia ha sido substituida por el experimento, la narración por la información.

La crisis del lenguaje simbólico, el "fin" de los (grandes) relatos y el ocaso de la experiencia, constituyen tres aspectos de la crisis del mundo moderno que han incidido negativamente en la formación de la vida narrable. La necesidad del ser humano de encontrarse situado en un tiempo y en un espacio solamente puede realizarse si somos capaces de utilizar la capacidad simbólica y, por lo tanto, narrativa: "Los símbolos hacen posible que el hombre recorra el trayecto que va desde un mundo sentido a un mundo con sentido. En este contexto, es conveniente insistir en el hecho de que los procesos de aprendizaje, que son imprescindibles para adquirir la 'estatura humana', no son sino praxis y ejercitaciones simbólicas” (Duch, 2002, p. 38).

Resulta interesante seguir a Benjamin en su razonamiento, para constatar que la narración tiene lugar en la experiencia, pero también en su transmisión. En un mundo, el moderno, en el que los procesos de transmisión, y por lo tanto los procesos pedagógicos, también se han visto seriamente afectados, la narración no puede tener lugar. Cuando lo que importa en la enseñanza en asegurarse una transmisión eficaz de la información, más que introducir en la conciencia del educando contenidos subjetivos capaces de hacer experiencia en él, los procesos pedagógicos de transmisión pierden gran parte de su virtualidad educativa. En el caso de la enseńanza de la historia, los resultados son letales. El narrador, más que inventar, transmite, pero ¿qué transmite en realidad?: transmite la experiencia que va de boca en boca-un relato encadenado 
a muchas voces-pero también la esperanza en sus propias posibilidades. Por eso, transmite una memoria (Savater, I994, p. 30).

Si el aprendizaje se limita a ser un adiestramiento exclusivamente técnico, el ser humano se convierte en una mónada "preocupada exclusivamente por el éxito en el momento presente” (Duch, I997, p.IO4) y queda desconectado de las preguntas radicales. Esto es lo que ha sucedido en la modernidad. Por esta razón, la crisis de la narración es también, inevitablemente una crisis pedagógica. Es necesario insistir en esta idea: la narración está viva si se transmite. Sin transmisión, la narración desaparece. El narrador toma lo que narra de la experiencia, la que él mismo ha vivido, o bien la que le han transmitido. Pero, a su vez, hay narración en el momento en que esta experiencia es transmitida. La transmisión de la experiencia supone su recreación, porque la narración no se recibe pasivamente. Todo lo contrario: hay transmisión a condición de que la experiencia se reactive y reinterprete. Sólo es posible la auténtica transmisión, entonces, en la interpretación de lo transmitido. ${ }^{2}$ Por eso, experiencia, transmisión e interpretación resultan tres aspectos esenciales de la narración. El que escucha reaviva la experiencia. Es necesario insistir en ello, por cuanto la modernidad se caracteriza esencialmente por una crisis gramatical. Es posible destacar, entonces, tres ideas fundamentales.

En primer lugar, la fuente del relato es la experiencia. Todo relato es subjetivo, ya que la huella del narrador está constantemente presente. No se trata, en el relato, tanto de contar los hechos, cuanto de contar la experiencia que los sujetos hacen a partir de los que les pasa. Así, lo que el lector encontrará en el relato no es la historia de lo que sucedió sino la experiencia viva de lo sucedido por alguien. El relato cuenta una historia, pero no la cuenta como lo haría la historia científica, con datos, cifras, etc. El relato cuenta la historia vivida, subjetiva, del narrador. El relato, a diferencia de la crónica científica histórica, no busca la objetividad, porque sabe que la verdad nace en el lenguaje, y que esta verdad, como todo lenguaje, es múltiple, distinta, dependiente de aquel o aquella que la pronuncie. En segundo término, el relato hace referencia al pasado, narra el pasado, lo recuerda. No hay relato sin recuerdo. Y, en consecuencia, una crisis de nuestra facultad de recordar supone inmediatamente una crisis de la narración. La novela nace en soledad, y no necesita ni de la experiencia ni de la memoria. Se basta con la sola imaginación, con la fantasía del escritor, con la vivencia íntima o el lirismo. El relato, en cambio, vive de la memoria y de la imaginación y su componente es épico. Por último, el relato no necesita de la novedad, no pasa de moda. A diferencia de la información, el relato no vive del instante, de la fugacidad del presente. A la información no le interesa lo que sucedió hace tiempo, sino lo que acaba de suceder. El auge de la información lleva consigo el declive de la narración. Experiencia, memoria y durabilidad en el tiempo son los tres rasgos específicos de la competencia narrativa que el orden moderno ha puesto en crisis.

Pero hay un elemento de la narración de particular interés para la historia y su transmisión como experiencia. En su ensayo, Benjamin señala que el arte de narrar, como transmisión de experiencias memorables, está en declive porque está extinguiéndose el lado épico de la verdad, es decir: la sabiduría. Pero es específico de la narración que el narrador lo cuente todo, hasta el final. La palabra narrativa es, entonces, una palabra 
instalada en una épica pero también una palabra franca, una palabra que no oculta nada, que lo dice todo, que da voz a todos los que participan en la construcción de la trama. Por eso, recuperar la dimensión narrativa en la enseńanza de la historia es tratar de recuperar las acciones y las palabras de los hombres en el registro de sus hazañas, es verse obligado a contar la historia con franqueza, es contar tanto lo dicho como los silencios de los que todo decir surgen. Veremos que esta necesidad de decirlo todo en la historia es esencial después del siglo XX.

\section{Reinventar lo humano: la enseñanza de la historia y las lecciones del siglo XX}

En su ensayo "La crisis de la educación”, publicado en 1958, decía Hannah Arendt (1996)que toda situación de crisis nos obliga a volver a plantearnos preguntas y, sea que respondamos con nuevas o viejas respuestas, en cualquier caso solicita de nosotros que afrontemos la crisis formulando juicios directos (pp.185-208).

Una situación de crisis no es necesariamente un desastre, al contrario de lo que muchos puedan creer. Y si lo es, quizá lo sea en la medida que a ella nos limitamos a responder con juicios preestablecidos, o que nos volvamos incapaces de atender, con ojos nuevos y mirada atenta, a la esencia de un asunto que, en virtud de tal crisis, parece manifestársenos con toda su insolente desnudez.

En el caso de la crisis de la educación, Arendt pensaba que su esencia desvelada consistía en el hecho de la "natalidad", y concluía su ensayo afirmando que lo que nos interesa a todos -y no sólo a los pedagogos o a los especialistas de la educación-es perfilar nuestra actitud hacia la natalidad, el hecho de que todos hemos venido como recién llegados al mundo al nacer y de que este mundo se renueva de continuo a través de los nacimientos:

La educación es el punto en el que decidimos si amamos al mundo lo bastante como para asumir una responsabilidad por él y así salvarlo de la ruina que, de no ser por los nuevos y los jóvenes, sería inevitable. También mediante la educación decidimos si amamos a nuestros hijos lo bastante como para no arrojarlos de nuestro mundo y librarlos a sus propios recursos, ni quitarles de las manos la oportunidad de emprender algo nuevo, algo que nosotros no imaginamos, lo bastante como para prepararlos con tiempo para la tarea de renovar un mundo común. (p.208)

Estas ideas de Hannah Arendt pueden ayudarnos a centrar nuestras reflexiones en torno a la enseńanza de la historia y de su valor educativo dentro de un debate de mayor alcance en torno a las humanidades, permitiéndonos revisar nuestra conciencia de una supuesta "crisis" de este tipo de enseñanzas. Al revisar nuestra conciencia de tal crisis quizá sea conveniente comenzar tratando de evitar dos tipos de prejuicios fundamentales. 
En primer lugar, la nostalgia de pasados gloriosos que quizá nunca existieron en realidad y la actitud de una guerra defensiva frente a la técnica y al progreso científicotecnológico. Para contrarrestar ambos prejuicios tal vez sea preciso recordar-como dice Ciriaco Morón (1998) - que

las humanidades han estado siempre en crisis porque son disciplinas interdisciplinares, de autocrítica y sin resultados prácticos inmediatamente visibles. No se pueden oponer a la ciencia y la tecnología, porque son una forma de funcionar la mente distinta a como funciona en el trabajo científico, y sólo merecen sobrevivir si estudian con rigor un sector de realidad no abarcado por otras disciplinas, y si contribuyen a mejorar la vida del hombre. (p.7)

Reivindicamos las humanidades como quien se reivindica a sí mismo como humano, y lo reivindicamos porque quizá sospechamos que un sistema educativo no puede centrar sus únicos esfuerzos en transmitir unos contenidos con el único propósito de lograr encajar a los alumnos en la sociedad para que desempeñen con eficacia y competencia una actividad profesional, entre otras cosas porque, como todos sabemos, este objetivo de lograr un trabajo correspondiente a una vocación muy perfilada no está en absoluto garantizado para casi nadie.

Existen muchas maneras de justificar la importancia y el valor de una educación de corte humanista, y no es posible entrar aquí en un análisis muy detenido de todos los posibles argumentos existentes. Pero quizá uno que es muy conocido e inmediato es ese según el cual una educación humanística pondría una suerte de freno ético a una sociedad excesivamente consumista y a una cultura inmoderadamente tecnológica y utilitarista. Uno podría traer aquí en su favor diversos textos de escritores y pensadores autorizados por la tradición y la aureola de prestigio que les acompaña. Así, podríamos citar a Walter Benjamin (I97I), quien escribió que

al orientar desde un principio a los estudiantes hacia fines profesionales, se deja escapar, como algo estimulante, el poder de la creación. La misteriosa tiranía de la idea de profesión es la más profunda de las falsificaciones. Lo que tiene de más terrible es que todas ellas llegan al centro de la vida creadora, aniquilándola (...) Desde que la vida de los estudiantes está sometida a la tiranía de la utilidad y la profesión, semejante idea excluye la ciencia, porque no se trata de consagrarse a un saber que aleja del camino de la seguridad burguesa. (p.44)

A la Historia le ocurre lo que a otras disciplinas humanísticas, como la Filosofía: el primer reproche que se les puede hacer es que no sirven para nada realmente útil. Uno puede afirmarse en esta "inutilidad" como quien se protege de su enemigo en una fortaleza vacía y sin recursos, pero con la ventaja de saber que él ignora nuestra precaria situación. En este caso, lo mejor es, entonces, dejarle muy claro a la sociedad desde el principio que ámbitos de conocimiento como la Historia realmente nos sirven para nada y esforzarse en conducirla hasta el estado de un arte dotado con todas las libertades formales. Pero también -y aquí no hago sino recordar una reflexión antigua 
que Paul Valéry hiciese para la Filosofía-presionarla de modo que sea utilizable de algún modo buscando las condiciones apropiadas para ello. En cualquiera de los dos casos hay que pensar muy bien qué se entiende por "servir a algo" y por "utilidad" (Cfr. Bouveresse, I984, p.23). Sea cual sea el sentido que le demos a este término quizá convenga no perder de vista, como dice Emilio Lledó (1998), que

en un período de nuestra vida en que, por suerte, nos vemos obligados a estar en contacto con el saber y con la ciencia, la obsesión por ganarse la vida es la forma más miserable de perderla (...) El acoso de las imágenes sin cuerpo sólo puede compensarse si en las instituciones educativas no se renuncia a la vida que nos dan las Humanidades. Son nuestra memoria y, en consecuencia son nuestra sustancia, como colectividad y como historia. En ellas nos reconocemos y en ellas, de alguna forma, existimos, preexistimos y persistimos. Algo semejante a lo que ocurre en la memoria individual. Escoger la memoria es, paradójicamente, escoger una buena parte del futuro. (p.I67)

Ser es, esencialmente, ser memoria (Lledó, p.I2). Pero la memoria es, a menudo, peligrosa. Sobre todo cuando se pretende hacer uso de ella en una sociedad amnésica, como en parte es la nuestra. Como escribió Kundera (1996) en El libro de la risa y el olvido, "la lucha del hombre contra el poder es la lucha de la memoria contra el olvido" (p.ro). En la historia de esta lucha una educación histórica tiene mucho que decir.

Así, la educación, o incluso la reeducación de la memoria, puede ser uno de los grandes objetivos formativos de la enseñanza de la historia en relación al valor de una educación sensible a la condición humana. Para poder hacer efectivo tal objetivo, quizá la enseńanza de la historia debería ser algo más que la enseñanza de los hechos. Es necesario hacer pasar del hecho al acontecimiento, y hacer que la cadena de acontecimientos que se muestran logren tener sentido para quien los estudia a través de una trama o de un relato que se da como lectura y objeto de interpretación y discusión pública. En este "relato" lo que se narra es, quizá, las interrupciones del movimiento circular de la vida biológica, por así decir, esto es: lo "extraordinario" de la existencia humana en su discurrir histórico. Al transmitir lo extraordinario en el marco de una relación de aprendizaje, no hacemos otra cosa que mostrar narrativamente cómo es la vida, cómo nos trata la suerte o el destino a los humanos.

Es aquí donde las ideas de Arendt pueden resultar interesantes. Porque si la crisis de la "educación" muestra con relativa insolencia ante nosotros que la esencia de la actividad educativa es la natalidad y, por tanto, de ello cabe derivar como responsabilidad pedagógica fundamental el acogimiento de los nuevos y la protección de un mundo común, la esencia de la crisis de una educación "humanística" quizá nos muestre sobrecogedoramente que, como dice George Steiner, (Kearney, 1998) nuestra mejor tradición cultural en modo alguno "impidió que la civilización europea se hundiese cayendo en la más espantosa barbarie, en la crueldad y la violencia más extremas. En vez de ello, hasta puede que las incitara. Somos realmente muy vulnerables" (p.IOz).

Por eso mismo, y aunque muchos no estuvimos cuando ocurrió el acontecimiento más atroz del siglo XX-la introducción de los totalitarismos-porque llegamos 
después, cualquier reivindicación de una educación humanista, y con ella cualquier pretensión de fortalecer la presencia de disciplinas como la Filosofía, la Literatura o la Historia en el sistema educativo, debería poder acompañarse con una sólida reflexión crítica sobre el hecho de que quienes podían sentir emociones e incluso llorar evocando literariamente el sufrimiento de otro, sin embargo permanecían impertérritos cuando perpetraban su propio crimen. Y es que, señala Steiner (1990),

no parece realista pensar en la literatura, en la educación, en el lenguaje, como si no hubiera sucedido nada de mayor importancia para poner en tela de juicio el concepto mismo de tales actividades. Leer a Esquilo o a Shakespeare-menos aún 'enseñarlos' - como si los textos, como si la autoridad de los textos en nuestra propia vida hubiera permanecido inmune a la historia reciente, es una forma sutil pero corrosiva de ignorancia (...) Sabemos que un hombre puede leer a Goethe o a Rilke por la noche, que puede tocar a Bach o a Schubert, e ir por la mańana a su trabajo en Auschwitz. Decir que los lee sin entenderlos o que tiene mal oído es una cretinez. (p.I6)

Entonces, si nuestra tradición cultural humanista no pudo impedir la barbarie que hemos conocido, parece que estamos en un callejón sin salida ¿Qué puede aportarnos una educación de estas características que no sea una formación simplemente más completa a la que recibiríamos si las humanidades estuviesen ausentes de los planes de estudio? ¿Acaso se puede seguir manteniendo hoy aquel alegato que Thomas Mann (1997) pone en boca de Settembrini en La montaña mágica?: "Nosotros, los humanistas, tenemos aficiones pedagógicas....Seńores, el lazo histórico entre el humanismo y la pedagogía explica el lazo psicológico que existe entre ambas. No hay que desposeer a los humanistas de su función de educadores...,no se les puede arrebatar, pues son los únicos depositarios de una tradición, la de la dignidad y belleza humana” (pp.95-96). ¿De qué humanismo estamos hablando y qué lecciones nos proporciona el siglo XX para que podamos formularlo?

Quizá una posible respuesta nos la pueda ofrecer la misma Arendt: el humanista, porque no está especializado, lo que hace es ejercitar una facultad de juicio y gusto que está más allá de las coacciones que impone cada especialidad concreta: "Este humanismo es el resultado de la cultura animi, de un actitud que sabe cuidar, conservar y admirar las cosas del mundo". En este sentido, una educación humanística es una educación en la que aprendemos a estar por encima de toda clase de especializaciones y filisteismos, "siempre que aprendamos el modo de ejercer nuestro gusto con libertad". Al hacerlo así, quizá logramos cultivarnos, o ayudar a cultivar a otros, si sabemos cómo elegir nuestra compañía entre los hombres, entre las cosas, entre las ideas, tanto en el presente como en el pasado (pp.237-238).

En definitiva, lo que una cultura humanista debería poder aportarnos, no es quizá tanto un conjunto de argumentos arrojadizos contra los males de una supuesta cultura tecnológica-como si la ciencia y la tecnología no fuesen ellas mismas logros también humanos, con independencia de sus aplicaciones-y mucho menos motivos para sentirnos más identificados con nuestras raíces nacionales o con nuestra memoria colec- 
tiva nacional, sino quizá un sentido de pertenencia no tanto a una comunidad nacional concreta como a esa otra comunidad moral que es la humanidad. Y junto a ello la posibilidad de transmitir una memoria ética y unos valores que permitan a las nuevas generaciones practicar una ética de la vigilancia más segura de la que, al parecer, practicaron sus mayores. Para hablar de esta supuesta misión humanizadora de la educación tenemos que empezar definiendo un marco de interpretación suficientemente amplio en el que inscribir lo que entendemos por humanismo. A la postre, ese humanismo, o ese nuevo humanismo, no defiende tanto un sentido muy enraizado de la identidad, sino una identidad de tipo rizoma, es decir, una identidad cuyas raíces son múltiple y se extiende, más que buscar hondura y profundidad vertical.

Concretando, creo que tenemos, al menos, dos posibilidades. En primer lugar, un humanismo sin historia y, en segundo término, un humanismo sensible a la historia. $\mathrm{O}$ dicho de otro modo: un humanismo atemporal o un humanismo atravesado por toda la magnitud del tiempo. El primero es un humanismo todavía sujeto a la herencia del yo trascendental. Define sus valores desde arriba, no desde abajo, y el tipo de hombre y mujer por el que apuesta nada tiene que ver con el hombre y mujer del subsuelo del que hablaba Dostoiveski. Su casa, claro está, no es la "casa de los muertos", y aunque su mundo es un "mundo aparte", su lugar no parece situarse en el más acá de un infierno, sino en el más allá de un cielo, de un paraíso, de una ciudad ideal. Es un humanismo perfectivo, donde esa perfección es un horizonte final que justifica que en el camino que a él conduce los hombres sufran y tengan que soportar lo insoportable. Justifica el mal y el sufrimiento de la gente como los amigos de Job el dolor de éste. Es un humanismo en el que el humanista sigue preocupándose de sí mismo, cuida de sí y de su perfección individual, cuida de lo suyo y de los suyos, pero en realidad está siempre desatento de lo que les pasa a los demás. No cuida de sí para aprender a cuidar de los demás. Nunca piensa que la peste que a los demás aniquila o que la ceguera blanca que ciega a los otros a él mismo pueda ocurrirle alguna vez. Es un humanista, y es un humanismo que sabe leer, pero entiende que la buena literatura es un lujo para espíritus selectos, y cada vez que piensa en el pasado lo piensa como quien piensa en la gran herencia de la cultura occidental, orgullosa de sí misma, incomparable, sólida e inalterable. Es un humanismo, por tanto, inocente, en el peor de los sentidos: inocente políticamente-yo no hice tal cosa, yo no cometí ese crimen-y por tanto, también, éticamente indiferente: poco deferente hacia los demás. Es el humanismo que no prevé lo que se nos puede avecinar, que a pesar de todo nada aprende del pasado, de la memoria, y que cada vez que arremete contra el totalitarismo y sus bestialidades lo hace señalando: esto es consecuencia de nuestro alejamiento de Dios. Volvamos a El y acabaremos con el mal. Este humanismo no sabe lo que sí sabía el protagonista de $\mathrm{La}$ Peste, de A. Camus (I997), cuando la epidemia parece haberse resuelto y la ciudad lo festeja despreocupada:

Oyendo los gritos de alegría que subían de la ciudad, Rieux tenía presente que esta alegría está siempre amenazada. Pues él sabía que esta muchedumbre dichosa ignoraba lo que se puede leer en los libros, que el bacilo de la peste no muere ni desaparece jamás, que puede permanecer durante decenios dormido 
en los muebles, en la ropa, que espera pacientemente en las alcobas, en las bodegas, en las maletas, los pañuelos y los papeles, y que puede llegar un día en que la peste, para desgracia y enseńanza de los hombres, despierte a sus ratas y las mande a morir en una ciudad dichosa. (p. 578)

Pero hay, quizá, la posibilidad de pensar en otro humanismo, en otra forma de pensar la vocación humanista de la educación. Es un humanismo que no renuncia a una cierta utopía, pero que a la vez por no ignorar lo que la historia nos trae como fraude y asesinato, es desencantado y sumamente crítico. Este humanismo puede aprender de la decepción, porque está dispuesta a aprender de lo negativo, de la experiencia del dolor: es un aprender del y después del padecer. ${ }^{3}$ Es un humanismo que no se funda en una esencia ideal del ser del hombre o de los valores de su naturaleza, sino que se funda en la experiencia de Auschwitz, de Kolima y de la nación de los desamparados del mundo de hoy, los nuevos Lager: Angola, Burundi....

Se trata pues de un humanismo que lee a Goethe, pero que sabe que la lectura de Goethe o de Novalis no supuso una barrena ni un freno para la barbarie. Es un humanismo que los sigue leyendo, pero también lee al Dante recitado por Primo Levi en Si esto es un hombre, que lee los tratados sobre la dignidad humana de los italianos renacentistas, pero también La especie humana de Robert Antelme o La condición humana de Malraux. Que escucha la música de Wagner o de Mozart, pero también se atreve a aterrorizar su propia imaginación musical escuchando a Oliver Messiaen o a Arnold Schönberg. Este humanismo cree menos en el Hombre que en los "hombres", y le preocupa poco insistir en hacer panegíricos de la idea de una Humanidad en términos absolutos o universales. Es un humanismo que sabe guardar en la memoria lo peor que los hombres han hecho en la historia y a la vez sabe distinguir la falsa realidad que se nos impone con el simple hecho de decir la verdad, de no mentir. Porque distingue bien entre hablar de la verdad o sobre la verdad y hablar la verdad, permitiendo que la conversación sobre ella no se cancele antes de haber pronunciado todas las palabras, antes de que hayan intervenido todas las voces. Es un humanismo que procura no ser ni orgulloso ni inocente o ingenuo. Este humanismo se sostiene, entonces, en una ética cuyo punto de partida es la experiencia de lo que no es aceptable, de lo intolerable, del dolor y el sufrimiento. Su fundamento no se sitúa en ser el origen de situaciones ideales, sino en la resistencia frente a lo insoportable, por eso sus categorías no son conceptuales, sino aquellas que tratan de nombrar lo indecible del acontecimiento del dolor. Su palabra no es lógica, sino poética, y su entraña agonal y patética. ${ }^{4}$

Este humanismo, por tanto, sabe que en el contexto de nuestra civilización moderna-administradora y racionalizada-las preguntas verdaderas no son sólo las que se formula la ciencia o el conocimiento experto, sino los interrogantes que los hombres comunes todavía pueden hacerse, las preguntas relativas, quizá, como decía Weber, al verdadero arte, a la verdadera felicidad, al verdadero ser. En su intento de acercarse a una respuesta a estas preguntas, una respuesta que nunca es un cierre, el humanista del que hablo se deja acompañar de muchas voces; voces como la de Tolstoi, que tenía claro que la ciencia carecía de la facultad de hacer sentido porque no podía responder a la cuestión inquietante: ¿Qué hemos de hacer? ¿cómo hemos de vivir? 
Por tanto, este humanismo no alardea de un culto al hombre, en general o en particular, ni predica su fe en su noble naturaleza o sus creaciones, sino que su punto de partida, insisto, es Auschwitz y Kolima, por ejemplo. Pero al mismo tiempo este humanismo cree en la posibilidad de realizar un cierto bien, es decir, no el triunfo universal del bien ni la realización de un paraíso en la tierra, sino del bien que el hombre concreto, singular, contingente puede hacer. ${ }^{5}$

El humanismo del que hablo parte, por tanto, de la realidad del mal-la anulación de la libertad, la supresión de la pluralidad, la reducción de la vida a nuda vida-y de la posibilidad concreta del bien. Y sabe que el vínculo que une la indeterminación y la contingencia, nuestros límites como humanos y nuestra pluralidad con la posibilidad de instaurar una forma de vida valiosa en la tierra es la educación. Pero sabe, también, no ser inocente, como decía antes. Sabe, en los términos en los que admirablemente lo dice Robert Musil (I993), que "hemos conquistado la realidad y perdido el sueño. Ya nadie se tiende bajo un árbol a contemplar el cielo a través de los dedos del pie, sino que todo el mundo trabaja" (p. 48). Este humanismo, por tanto, tiene menos preocupación en justificar la esencia del ser humano, o en dejar bien trabada la estructura de su formulación teórica, que en preguntarse qué hace que los seres humanos puedan cuidar mejor de la existencia de sus congéneres. Y como no es ingenuo, sabe que existen el drama y la tragedia, porque existir es estar afuera, es exponerse y arriesgarse. Por tanto, sabe que existe el dolor y la muerte. Pero también sabe que aunque hemos de morir no hemos venido a este mundo a esperar tranquilamente la muerte, sino a iniciar algo nuevo. Sabe que el ser humano puede superar la secuencia natural de su propio nacimiento y renacer siempre que inicie algo nuevo junto a otros con la acción y la palabra. Es decir, siempre que se le deje un espacio para crear.

\section{Enseñanza de la historia y testimonio}

Una enseñanza de la historia que sabe que la historia la escriben, casi siempre, los que vencen, pero que al mismo tiempo es sensible al hecho esencial de que en todo relato podemos ofrecer una versión interesada de nosotros mismos-como héroes o como víctimas-seguramente abandona algunas premisas que se nos han venido transmitiendo acerca de lo que forma la conciencia histórica: por ejemplo, los mitos fundacionales (Glissant, 2002, pp.62-63). Pero precisamente por ello, reconoce quizá el valor que tiene para la investigación histórica y su enseñanza la capacidad para dar testimonio de la singularidad de los acontecimientos narrados. Como forma de educar la memoria, esta capacidad para dar testimonio es una facultad central. ${ }^{6}$

Para profundizar en esta idea, voy a partir del Informe sobre los textos y cursos de Historia en los centros de enseñanza media elaborado en el seno de la Real Academia de la Historia, elaborado no hace mucho en Espańa. Se pueden destacar tres cuestiones principales en él. En primer lugar, los académicos señalan la importancia de la autonomía de la historia como disciplina y materia de estudio, lo que les conduce a cuestionar su adscripción al área de las "Ciencias Sociales, Geografía e Historia” a partir de la aprobación, en I990, de la L.O.G.S.E. En segundo término, el Informe reitera con frecuencia su preocupación por el hecho de que la enseñanza de la Historia se limite, en cuanto 
a los contenidos de aprendizaje, a cuestiones relacionadas con la comprensión del mundo en que vivimos - esto es, cuestiones referidas al tiempo presente-descuidando el estudio de los grandes acontecimientos del pasado, con lo cual uno de los principales objetivos de toda educación histórica-la memoria del pasado-quedaría eliminada. Por último, los académicos responsables del Informe destacan su preocupación por el hecho de que, a la luz de la realidad educativa vigente en los últimos años, hayamos pasado de una época de exaltación del nacionalismo español a otra en la que los elementos comunes del proceso histórico están a punto de perderse a favor de lo que nos diferencia. "En ocasiones-se señala en el Informe-daba la impresión de que la vieja Historia de Espańa se fragmentaba en múltiples historias regionales”. Esta fragmentación de la Historia de España, en el marco del Estado de las Autonomías, parece, según el Informe, desarrollarse en el fondo de una contradicción interna, la que supone haber criticado en el pasado el carácter nacionalista de la historia que se enseñaba y de reproducir, sin embargo, ese mismo planteamiento en las diversas Autonomías (Ortiz de Orduño, 1998).

Tras un resumidísimo repaso de la evolución de la enseñanza de la historia, el Informe destaca como principales elementos caracterizadores de la situación actual el "desdibujamiento e imprecisión, al menos en lo que se refiere a los elementos comunes", el énfasis en la historia de cada Comunidad Autónoma, es decir, en los elementos diferenciadores más que en los elementos comunes y "el predominio indiscutible de la contemporaneidad". Este juicio crítico se reitera en lo que se refiere al análisis que en el Informe se hace sobre los textos de historia vigentes: adolecen, por un lado, de fuertes lagunas en lo que se refiere al estudio de la Historia anterior a la época contemporánea y, por otra, ofrecen a los alumnos una visión "parcial y vaga" del proceso histórico español. La conclusión final del Informe es que el estado actual de la enseñanza de la historia en España dentro de los estudios secundarios se caracteriza por tres notas: sociologismo, pedagogismo y prevalencia de las circunstancias políticas. O lo que es lo mismo: una visión del pasado alejada del tradicional proceso cronológico, una exaltación de los métodos de enseñanza sobre los contenidos, y una utilización instrumental de la historia, cuya enseñanza está al servicio de objetivos ajenos a planteamientos académicos.

Si la historia, como se dice en el Informe, es el "territorio del hombre", y todo lo que los humanos hacemos se sostiene sobre el fondo irrenunciable de lo que hemos sido, entonces es imprescindible prestar atención a la memoria histórica, y con ella al pasado, a la cronología y a los acontecimientos. Quizá esta falta de atención al pasado que los firmantes del Informe subrayan no sea sino una manifestación más de los rasgos del tiempo en que vivimos, o mejor dicho, una expresión del hecho, característico de la modernidad, de que ha cambiado nuestra imagen del tiempo y, con ello, nuestra relación con la tradición. Sólo si somos conscientes de pertenecer a una tradición podemos ejercer una crítica a ella. Tomar conciencia de algo es estar dispuesto a la crítica. Sin embargo, nuestro tiempo se distingue de otras épocas y sociedades por la imagen que elaboramos del transcurrir, esto es, por nuestra consciencia de la historia. Es indudable que eso que, aun paradójicamente, llamamos tradición moderna es una expresión de nuestra conciencia histórica: por un lado, crítica del pasado y de la tradición y, por otra parte, tentativa por fundar una tradición sobre la base del principio del cambio 
y de la historia (Paz, I999, pp.4I5-4I6). Por eso resulta sorprendente la pretensión de transmitir una historia sin memoria del pasado, sin análisis y crítica de lo ocurrido, sin valoración, en suma, y por tanto presencia, de la memoria histórica.

Una primera pregunta, de orden general, que podemos formularnos es: ¿Qué significa educarse mientras se aprende la historia? ¿Y de qué historia se trata? Aunque tal vez no se pueda establecer una distinción muy nítida entre este tema y la problemática relacionada con la "función social del historiador", deseo dejar claro ya desde el principio que no entraré aquí en la consideración de esto último. No interesa ahora analizar la competencia social de los historiadores sino, en todo caso, mostrar a la luz del planteamiento arendtiano de qué historia tenemos que hablar cuando es necesario testimoniar la experiencia de los vencidos. Lo que interesa es hablar de la crónica que la memoria del pasado relata-el recuerdo de las víctimas - en vez de las explicaciones que los historiadores realizan. A partir de aquí será entonces posible replantear también lo que tiene de educativo el aprendizaje de una historia que no olvida la crónica que la memoria es capaz de relatar.

Todo esto, plantea un primer problema: dar por supuesto que en relación a asuntos tales como las humanidades y la historia es posible invocar a una cierta teoría, aunque se trate, si se quiere, de una especie de "teoría educativa". Para salir del paso diré que en mi tratamiento de la cuestión no se encuentra la intención de una invocación de este tipo. Más bien considero, con George Steiner (1998), que "en las humanidades, la teoría no es más que intuición que se vuelve impaciente” (p.I8). Lo que sí es más evidente es que una reflexión sobre la enseńanza de la historia debe hacerse dentro de un replanteamiento crítico del valor de las humanidades.

A propósito de esto último deseo alejarme tanto como me sea posible de la polémica suscitada en Espańa en relación a una supuesta crisis de la enseńanza de la historia. Mi preocupación no es, en este sentido, una preocupación didáctica, o relacionada con los contenidos que los alumnos deben o no aprender en estas materias. Interesa más, en todo caso, recuperar la fuerza educativa de la rememoración y de la imaginación narrativa dentro de la experiencia de aprender historia, es decir, del aprendizaje de los modos de relación con el pasado. No obstante, esta formación de la memoria histórica, así como el desarrollo de la imaginación narrativa, quizá podrían funcionar, en contextos educativos, a modo de principios orientados a la formación política y al desarrollo de un sentido de ciudadanía en sentido cosmopolita. Pues, como ha escrito J. Habermas (I998), "sólo una ciudadanía democrática que no se cierre en términos particularistas puede, por lo demás, preparar el camino para un status de ciudadano del mundo o una cosmociudadanía, que hoy empieza a cobrar ya forma en comunicaciones políticas que tienen un alcance mundial" (p.643).

Al plantear así mi propuesta soy consciente de que estoy considerando en una determinada dirección la filosofía política contendida en toda educación histórica. Indudablemente, una educación histórica no tiene la última palabra en la formación política y democrática del individuo, pero al mismo tiempo el aprendizaje de la historia es muy importante para proporcionar madurez a este tipo de educación, porque nos permite relacionarnos de manera crítica con el pasado y aprender a valorar reflexivamente la dimensión histórica de nuestros problemas actuales. 
El anteriormente citado Habermas (I990) ha sostenido, en el marco de una polémica, reseñada más atrás, y que por supuesto no es fácil extrapolar a nuestro contexto, que el "patriotismo constitucional" es la única forma de patriotismo aún a nuestro alcance y todavía posible para el pueblo alemán después de Auschwitz (p.I5I y ss.) Pero si por ese patriotismo de la Constitución hay que entender una cierta fidelidad y lealtad a los principios democráticos constitucionales, la polémica suscitada en España sobre el tema que nos ocupa debería poder enriquecerse con debates intelectuales de mayor alcance en los que-desde un cierto distanciamiento crítico-fuésemos capaces de considerar hasta qué punto es todavía defendible un sentido más universal de la ciudadanía que no fuese contradictorio con un sentido de pertenencia y responsabilidad con la comunidad en la que se vive o se siente como propia.

De acuerdo con esto, personalmente tendería a pensar que la enseñanza de la historia no tiene por qué quedar comprometida en reforzar la espańolidad de los españoles o fortalecer su unidad étnica y cultural, porque, parafraseando un texto reciente de Maurizio Virolli (I997) sobre el nacionalismo y el patriotismo, la conexión entre ser españoles y ser buenos ciudadanos no funciona como una correlación necesaria. No se tiene que ser genuino o verdadero español-en sentido etnocultural-para ser un buen ciudadano (p.2I7). En la enseńanza de la historia asuntos como estos deberían poder tenerse más claros de lo que muchas veces están.

Lo que me parece bastante exacto es que frente a quienes pueden considerar que el problema principal de la enseńanza de la historia reside en lo que el alumno debe saber y desconoce-los contenidos que debe aprender-entiendo que la cuestión reside más bien en que los alumnos carecen, por desgracia, de un entramado conceptual mínimamente apropiado para entender los hechos históricos que se les exponen en la enseńanza. Por tanto, dedicarse a mostrar, al modo tradicional puramente descriptivo, una cantidad excesiva de conocimientos sin detenerse a explicar los conceptos y sin construir los relatos que los hacen comprensibles es dejar el campo abonado para que la enseñanza de la historia invita a dormir una larga siesta.

Por eso hay que cambiar el sentido de la enseńanza de la historia y pasar, como mínimo, de una enseñanza memorística y excesivamente orientada en un sentido enciclopédico-culturalista a otra en la que-a través de un marco narrativo y literario-la memoria, la capacidad de recordar activamente el pasado, y la capacidad de imaginarnos a nosotros mismos evocando experiencias pasadas nos permita dar sentido, no solamente a lo que ocurrió, sino también a nuestro presente como algo relacionado con un pasado que todavía puede enseñarnos algo. Porque, como decía Hannah Arendt en un interesante ensayo sobre el concepto de Historia, la tarea del historiador "consiste en hacer algo que sea digno de recuerdo" (p.52).

Al destacar este objetivo educativo deseo dejar claro que en el proceso de enseñar la historia uno debe ejercer una cierta responsabilidad moral relacionada con lo que, en esa giro de la mirada hacia el pasado y a la tradición, pretende legitimar. En este sentido convendría quizá señalar los usos, o quizá mejor, los abusos de lo heredado, de la tradición, de aquello que se percibe como permanente que no buscan sino demostrar la bondad de aquello se quiere conservar a cualquier precio o demostrar, por el contrario, la necesidad del cambio radical, esgrimiendo la tradición interrumpida. 
Es indudable la importancia que tiene el trabajo de la memoria en la investigación y la enseñanza de la historia. El historiador tiene mucho que aprender de ella desde el punto de vista de lo que los nuevos métodos de investigación histórica, centrados en los relatos y los testimonios orales, pueden aportarle (Cuesta Bustillo, 1998). Pero precisamente por ello, debe ponerse cuidado a la hora de perfilar el sentido del trabajo del recuerdo y la naturaleza de la práctica del historiador. Mientras que la memoria es, por naturaleza, subjetiva, selectiva, y poco proclive a los alineamientos cronológicos y a las reconstrucciones globales, el historiador, como dice Enzo Traverso (I999, pp. I32-I33), tiende a ver en lo que un testigo percibe como acontecimiento esencial y singular en su vida una etapa de un proceso más amplio. Su trabajo consiste en inscribir la singularidad de una experiencia vivida-individual o colectivamente - en su contexto histórico global, procurando esclarecer sus causas, condiciones, estructuras y dinámica conjunta. Es decir: debe aprender de las memorias y de los testimonios, pero tiene que pasarlos por la criba de la verificación objetiva, empírica, documental, factual. Puede haber una singularidad absoluta de la memoria, sin duda, pero la singularidad de la historia es siempre relativa. Meditar sobre esta distinción seria muy provechoso para quienes, dentro de determinadas comunidades, se empeñan en cambiar un nacionalismo por otro y en recordar su supuesta condición de víctimas del pasado con la pretensión de arrogarse el derecho de presentarse como verdugos del presente.

\section{La transmisión de una memoria ejemplar}

En este punto podemos formularnos una pregunta: ¿de qué sirve realmente conocer los hechos del pasado, especialmente los que se revisten de un carácter trágico tal que condicionan y determinan incluso nuestro presente? La enseñanza de lo histórico nos plantea la cuestión de la relación con el pasado. Este problema mantiene su vigencia con independencia del tipo de historia que se pretenda enseñar. Y aunque es cierto que siempre se enseńa desde un presente, desde una cierta actualidad, incluso al enseñar la historia de lo actual o de lo contemporáneo lo que se enseña es la cadena de hechos que se han sucedido, que han pasado. O sea, que al enseńar la historia lo que mostramos es una suerte de relación-desde un presente-con el pasado.

¿Cómo nos relacionamos con el pasado? ¿Asegurándonos en qué conjunto de gestos y actitudes? Para responder a estas preguntas quizá convenga recordar que lo que se pone en cuestión cuando nos interrogamos por nuestra relación con el pasado no es quizá tanto "la verdad" de los hechos sino "el valor mismo de la verdad" (Larrosa, I996, pp. 4I2 y ss.) Puede distinguirse entre una orientación a la verdad que nos inquieta, que nos desestabiliza, que de algún modo no nos deja inalterados, y otra que tiende al conformismo, al autoconsuelo y a plantear las cosas sin problematizarlas. De acuerdo con este esquema, al enseñar mediante la historia los hechos del pasado podemos incurrir en varias formas de hacer de esa relación con el pasado una relación en cierto modo inofensiva.

Por un lado dar a leer el pasado sin relación con el presente, es decir, como un simple pasado y, en segundo término, aboliendo la distancia histórica, o sea, reconstruyendo la historia para ver en el pasado las causas del presente y explicar así la "necesi- 
dad" de éste. Es como si al ver el pasado nos viésemos a nosotros mismos pero con otro decorado y otros vestidos. Una alternativa a mostrar el pasado como algo indiferente y a-problemático es verlo como un texto que se nos da a leer en relación al modo como leemos el presente. Planteadas así las cosas, quizá entonces lo que tenemos que hacer al enseñar cosas tales como la historia es, por un lado, salvar lo reprimido y lo olvidado en el relato que construyen los vencedores y, por otro, subrayar la diferencia entre el pasado y el presente, es decir, la brecha que existe en la continuidad del tiempo. Hay que atreverse a considerar los acontecimientos que rompen la continuidad de la historia, que fracturan el tiempo en dos, y aprender a redescubrir el pasado por nosotros mismos, leyendo a quienes lo integran, por así decir, como si nadie los hubiera leído antes. Quizá ahí reside gran parte de nuestros problemas: en que, a pesar de todo, e incluso frente a la extensa charlatanería de todo el neoconservadurismo en educación y en política, la educación no puede avanzar sin un mínimo de conservación. Es decir, que la educación no puede avanzar sin un mínimo de consideración hacia la tradición y que debe, no obstante, ejercerse en un mundo que ya no está estructurado ni por la autoridad ni por la tradición.

Es indudable que este conocimiento es fundamental para la educación de los ciudadanos. Sin embargo, es importante saber definir con exactitud el tipo de relación que establecemos con él, a través de la formación de la memoria. ${ }^{8}$ En este punto, me gustaría traer a colación aquí una útil distinción de Tzvetan Todorov (1998) entre dos clases de memoria). Todorov ha distinguido entre una memoria literal, que es aquella en la que el recuerdo queda retenido en su absoluta literalidad y permanece por ello intransitivo y sin posibilidad de conducir más allá de sí mismo, de modo que el recuerdo sigue operando sobre el presente condicionándolo; y una memoria ejemplar que, sin negar la singularidad del suceso, lo recupera como una manifestación entre otras de una categoría más general, sirviendo como modelo o ejemplo para comprender situaciones nuevas e incluso diferentes. Se trata de un trabajo auténticamente pedagógico de la memoria, y tiene dos fases.

Por un lado, se trata de neutralizar-pero obviamente no olvidar-el dolor y el sufrimiento que produce el recuerdo del suceso en cuestión y, por otra parte, se trata de abrir ese recuerdo a la analogía y a la generalización, dando así la oportunidad de construir un exemplum para extraer una lección. Estas dos operaciones de la memoria son cruciales para que el trabajo del recuerdo sea una actividad conectada con una cierta idea de la educación. Porque sólo si han cesado la ira y la indignación la memoria puede hacer bien su trabajo, y porque sólo trascendiendo el suceso recordado y generalizándolo se puede hacer de las lecciones del recuerdo lecciones que sirvan para el futuro. Por eso, puede decirse que no habrá beneficio moral alguno para el sujeto que recuerda, o que transmite un relato del pasado de su comunidad o de su nación, si la evocación consiste meramente en instalarse en el "buen papel" - el del héroe o el de la víctima-de ese relato histórico. Esta memoria ejemplar, por lo demás, está conectada con la experiencia del lenguaje, que por esencia es comparativo, ya que una misma palabra puede designar una infinidad de cosas. ${ }^{9}$

Desde el punto de vista de esta segunda modalidad de memoria, la historia, y la transmisión de los hechos y acontecimientos del pasado, se hace asimismo ejemplar, lo 
que conlleva la toma de conciencia de determinados deberes, tanto a los historiadores como a los profesores encargados de la enseñanza de la historia. El primer deber es epistemológico, y consiste en la obligación de encarar la verdad. Quien falsifica la verdad de la Historia -y esto a pesar de que la historia implica siempre un mundo de acontecimientos interpretados e interpretables, y por tanto la presencia de un cierto conflicto de interpretaciones - no merece el nombre de historiador, sino el de propagandista a lo sumo. Pero este deber no es suficiente para justificar la existencia de un discurso. Además hay que hablar de un deber ético y político, ya que nuestro mundo es plural e infinito, y es sumamente fácil, como escribió Hermann Broch (1995) en Los inocentes, acabar con un solo movimiento de la mano la diversidad del mundo (p.37). Este deber concierne, no tanto a los hechos del pasado, sino a los del presente. No se trata, por tanto, de preguntarse por lo que ocurrió, sino por lo que se debe hacer aqui y ahora para mejorar las condiciones de nuestro presente (Todorov, I999, pp. I59-I60).

Esta idea de una historia ejemplar tiene que ver, en definitiva, con la esencia misma de la tarea de la historia, al menos desde la tradición establecida a partir de Heródoto, a quien Cicerón llamó pater historiae. Se trata de salvar las hazańas humanas de la trivialidad que siempre se deriva del olvido, que es un rasgo muy acuciado en nuestras sociedades actuales, es decir, en lo que se ha dado en llamar la "sociedad de la información". Nuestras sociedades son, en efecto, marcadamente pobres en la transmisión de experiencias memorables. La falta de memoria hace que las cosas y las personas, sus hazañas y sus palabras, se condenen al ave de rapińa del olvido, al igual el cuerpo del hermano de Antígona. Por eso, si los mortales consiguen dotar a sus proezas, a sus trabajos, a sus gestas y palabras de un cierto grado de duración en el tiempo, y no sólo de presencia en el espacio, estas cosas llegarán a formar parte de un mundo de lo perdurable, y aunque quizá no de lo infinito, sí de lo inmortal y memorable. La capacidad que permite que esto se logre es, desde luego, Mnemosine, la Memoria, la madre de todas las musas. Por eso, Historia y memoria van juntas, con las matizaciones señaladas más atrás y otras que sin duda pueden hacerse, junto a la poesía, ya que es labor del historiador y del poeta hacer que algo humano y memorable sean digno de recuerdo. Lo que ellos cuentan es la crónica de lo extraordinario.

Pero dentro de lo "extraordinario" se encuentran esos "acontecimientos" desgarradores de la Historia, aquellos que separan el antes y el después, el pasado y el futuro (Traverso, 1997 y Bárcena y Mèlich, 2000). En su intento de exploración y de enseńanza de tales acontecimientos, la Historia se encuentra muchas veces desvalida, en tanto que disciplina científica, incapaz de decir lo indecible, pero que tiene no obstante que ser contado y transmitido para la enseńanza de otros. Es entonces cuando tiene que apoyarse, no sólo en la memoria y en los testimonios de los supervivientes de tales acontecimientos, sino también - por su valor intrínseco-en la palabra testimonial por excelencia: la palabra poética. Pues, como escribió Octavio Paz (1999), un poema que no intentase luchar contra la naturaleza de las palabras obligándolas a ir más allá de sí mismas y de sus significados relativos, una poesía que no trate de decir lo indecible, podría quedarse también en mera manipulación verbal (p. 23I).

En este sentido, el conocimiento del pasado ayuda a combatir los males del presente cuando afrontamos, tanto en la investigación histórica como en su transmisión, el reto 
de la comparación, y cuando nos planteamos con honestidad y rigor preguntas tales como ¿por qué cuento esta historia?, ¿A quién se la cuento?, ¿Cómo me sitúo yo en relación con ella?. De no hacerlo, quizá nos estaremos dando el gusto de mantener una buena conciencia, pero quizá al precio de transmitir una historia deformada y más bien poco ejemplar.

\section{Notas}

I. No puedo detenerme en una explicación detenida de este concepto ni en la historia de su introducción en la filosofía. Me limito aquí a señalar que entiendo por acontecimiento aquello que da a pensar, lo que permite hacer experiencia y lo que rompe con la idea del tiempo de la historia como continuidad. En este sentido, todo acontecimiento posee una singularidad propia, y como tal es incomparable con cualquier otro, pero solamente desde el ángulo de la relevancia ética, subjetiva y existencial que tiene para el sujeto. Desde el punto de vista de sus consecuencias políticas, los acontecimientos históricos, en cambio, deben poder compararse, para poder extraer lecciones futuras de ellos para el presente, pero no con el objeto de entrar en una guerra de memorias, sino con el fin de recordarlos ejemplarmente. Ver, sobre esta idea, aparte de lo que luego diré en este artículo: Bárcena (200I); Le Goff (199I); Rosa, Bellelli y Bakhurst (2000): Tadié (1999); Todorov (1998), (1999) y (2002).

2. "El narrador toma lo que narra de la experiencia: la suya propia o la transmitida. Y la torna a su vez en experiencia de aquellos que escuchan su historia. El novelista, por su parte, se ha segregado. La cámara del nacimiento de la novela es el individuo en su soledad" (Benjamin, 1998, p.II5).

3. Este aprendizaje de la decepción es, por ejemplo, la experiencia del aprendizaje típicamente proustiano, en $A$ la récherche du temps perdu, tal y como lo formuló brillantemente Deleuze (1995). Una explicación previa del mismo puede encontrarse en: Bárcena y Mèlich (2000, pp.I49-190).

4. La enseńanza de la historia, como crónica de los acontecimientos extraordinarios que dan a pensar, requiere de una ética de esta naturaleza, que sepa subrayar la radical asimetría entre la promoción del bien y la erradicación del mal. Dicho con Foucault, se trataría de lo siguiente: "En lugar de hablar de una libertad esencial, habría que hablar mejor en términos de agonismo - de una relación que es al mismo tiempo de incitación recíproca y de lucha; esto es, no tanto una relación de oposición frente a frente que paraliza a ambos lados, como de una provocación permanente". Foucault (1982, p. 222).

5. Todorov (2002) se refiere a este humanismo moderno como "humanismo crítico" (p. 365).

6. En relación a la voz testimonial, de aquellos que han sobrevivido a situaciones límite como campos de concentración y exterminio, resulta muy interesante la reflexión elaborada por Claudine Kahan en el sentido de que una vez que el relato de los supervivientes se transforma en escritura la memoria de lo de lo transmitido se torna, inevitablemente, una memoria ficticia, es decir, una "ficción", y el propio testimonio en algo "fabulador", por lo que de literatura ella misma contiene. Con ello se incrementa la distancia entre lo vivido y su relato. Ver: Kahan, C. (1999, p. 497).

7. Se sabe que el derecho a escribir la Historia era una de los privilegios que concedía la victoria. La experiencia del siglo XX muestra hasta qué punto es necesaria la memoria y el testimonio como formas de componer la historia de los vencidos. Pero quizá convenga aquí distinguir dos planos, el histórico y el ético. Lo que en el plano histórico es plenamente legítimo, en el ético es, al menos, discutible, pues siempre cabe preguntar si reivindicarnos como víctimas nos confiere mérito suplementario alguno.

8. Como es obvio, no puedo agotar todos los temas que subyacen a la compleja problemática de la memoria. Junto a la defensa del concepto de "memoria ejemplar" defendido por 
Todorov, me limitaré aquí a sugerir que la oposición entre "memoria" e "historia" resulta una defensa teóricamente controvertida si no se distingue adecuadamente entre memoria primaria - el recuerdo personal de un sujeto de sus propios acontecimientos y experiencias vividas-y memoria secundaria, que es el resultado del trabajo crítico sobre la "memoria primaria". El trabajo del historiador se refiere a esta segunda, mientras que nada puede decir de la primera, salvo aprender de los testimonios que ella aporta. Ver: Todorov (2002, pp. I9I2I2).

9. Dentro del debate sobre la "unicidad" y "singularidad "de los acontecimientos desgarradores de la historia, y en concreto sobre Auschwitz, existen puntos de vista diferentes. Una corriente muy extendida se centra actualmente en lo que podríamos llamar la "reflexión comparativista", que sigue cuatro registros básicos: a) histórico-jurídico; b) ético; c) filósofico: y d) literario. Como representantes de cada uno de estos registros teóricos puede citarse: Ternon (1995); Todorov (199I); Brossat (1996); Parrau (1995) y Coquio. (1997).

\section{Referencias}

Agamben, G. (200I). Infancia e historia. Destrucción de la experiencia y origen de la historia. Buenos Aires: Adriana Hidalgo Editora.

Arendt, H. (1996). Entre el pasado y el futuro. Barcelona: Península.

Arendt, H. (1958 Octubre). The Modern Concept of History. Review of Politics, 20 (4), 570-590.

Bárcena, F. (200I). La esfinge muda. El aprendizaje del dolor después de Auschwitz. Barcelona: Anthropos.

Bárcena, F. y Mèlich, J.C. (2000). La educación como acontecimiento ético. Natalidad, narración y hospitalidad. Barcelona: Paidós.

Barrios, M. (2002 Marzo) Pobreza de experiencia y narración. Un paseo por los alrededores de Walter Benjamin. Archipiélago, 50, 3I-4I

Benjamin, W. (197I). Mythe et violence, Paris: Denoel.

Benjamin, W. (1989). Discursos interrumpidos, vol. I. Madrid: Taurus.

Benjamin, W. (I998). Iluminaciones, vol. IV: Para una crítica de la violencia y otros ensayos. Madrid: Taurus.

Bouveresse, J. (1984). Le philosophe chez les autophages, Paris: Minuit.

Broch, H. (1995). Los inocentes. Barcelona: Lumen.

Brossat, A. (1996). L'Épreuve du désastre. Le XX siècle et les camps. París: Albin Michel.

Camus, A. (1996). Obras Completas, 2. Madrid: Alianza.

Coquio, C. (1997). L’Éxtreme, le génocide, l'experience concentrationnaire. Productivité et apories de trois concepts. Critique, 600 (338-364)

Coquio, C. (Comp.) (1999). Parler des camps, penser les génocides. Paris: Albin Michel.

Cuesta Bustillo, J. (Ed.) (1998). Memoria e Historia, Ayer, 32 (número monográfico).

Deleuze, G. (1995). Prousty los signos. Barcelona: Anagrama.

Duch, Ll. (1997). La educación y la crisis de la modernidad. Barcelona: Paidós.

Duch, Ll. (2002). Antropología de la vida cotidiana. Simbolismo y salud. Madrid: Trotta.

Foucault, M. (2000). Nietzsche, la genealogía, la historia. Valencia: Pre-Textos.

Foucault, M. (1982). The subject and Power. En H.L. Dreyfus y P. Rabinow, P. (Eds.), Michel Foucault. Beyond Structuralism and Hermeneutics, Chicago.

García Carrasco, J. y García del Dujo, A. (200I). Teoría de la educación II. Procesos primarios de formación del pensamiento y la acción. Salamanca: Ediciones Universidad de Salamanca.

Glissant, E. (2002). Introducción a una poética de lo diverso. Barcelona: Ediciones del Bronce.

Habermas, J. (1990). Die Nachholende Revolution. Frankfort.

Habermas, J. (1998). Facticidad y validez. Madrid: Trotta.

Kahan, C. (1999). La honte du témoin. En C. Coquio (Ed.), Parler des camps, penser les génocides. Paris: Albin Michel.

Kearney, R. (1998). George Steiner. El precio de la cultura. En G. Kearney (Ed.), La paradoja europea. Barcelona: Tusquets. 
Kundera, M. (1996). El libro de la risa y el olvido. Barcelona: Seix Barral.

Larrosa, J. (1996). La experiencia de la lectura. Barcelona: Laertes.

Le Goff, J. (199I). El orden de la memoria. El tiempo como imaginario. Barcelona: Paidós.

Lledó, E. (1998). El silencio de la escritura. Madrid: Austral.

Lledó, E. (1998). Imágenes y palabras. Madrid: Taurus.

Manguel, A. (200I). En el bosque del espejo. Ensayos sobre las palabras y el mundo. Madrid: Alianza.

Mann, Th. (1997). La montaña mágica. Barcelona: Plaza y Janés.

Morón, C. (1998). Las humanidades en la era tecnológica. Oviedo: Ediciones Nobel.

Musil, R. (1993). El hombre sin atributos, vol. I. Barcelona: Seix Barral.

Ortiz de Orduño, J.Ma (Ed.) (1998). Historia y sistema educativo. Ayer, 30 (número monográfico).

Parrau, A. (1995). Écrire les camps. Paris: Belin.

Paz, O. (1999). Obras Completas, I: La casa de la presencia. Poesía e Historia, Barcelona: Galaxia Gutemberg-Círculo de Lectores.

Rosa Riveiro, A., Bellelli, G. y Bakhurst, D. (Eds.) (2000). Memoria colectiva e identidad nacional. Madrid: Biblioteca Nueva.

Savater, F. (1994). La evasión del narrador. En Autor, La infancia recuperada (pp. 25-49) Madrid: Taurus.

Steiner, G. (1990). Lenguaje y silencio. Ensayos sobre la literatura, el lenguaje y lo inhumano. Barcelona: Gedisa.

Steiner, G. (1998). Errata. El examen de una vida. Madrid: Siruela.

Steiner, G. (200I). Gramáticas de la creación. Madrid: Siruela.

Tadié, J-Y y M. (1999). Le sens de la mémoire. Paris: Gallimard

Ternon, Y. (1995). L'état criminel. Les génocides au XX siècle. Paris: Seuil.

Todorov, T. (1991). Face à l'extrême. Paris: Seuil.

Todorov, T. (1998). Les abus de la mémorie. Paris: Arléa.

Todorov, T. (1999). La morale des historiens. En C. Coquio (Ed.), Parler des camps, penser les génocides. Paris: Albin Michel.

Todorov, T. (2002). Memoria del mal, tentación del bien. Indagación sobre el siglo XX. Barcelona: Península.

Traverso, E. (1997). L'Histoire déchirée. París: Cerf

Traverso, E. (I999). La singularité d'Auschwitz. Hypothèsis, problémes et dérives de la récherche historique. En C. Coquio, C. (Ed.) Parler des camps, penser les génocides. Paris: Albin Michel.

Virolli, M. (1997). Por amor a la patria. Un ensayo sobre el patriotismo y el nacionalismo. Madrid: Acento Editorial.

Weinrich, H. (1999). Leteo. Arte y critica del olvido. Madrid: Siruela.

Zambrano, M. (1995). Las palabras del regreso. Salamanca: Amarú Ediciones. 